\title{
A biografia e a busca por uma dimensão individual da história
}

Biography and the struggle towards an individualist view of history

LORIGA, Sabina. O pequeno $x$ : da biografia à história. Belo Horizonte: Autêntica, 2011, 231 p.

\section{Luzia Gabriele Maia Silva}

luzia.gabriele@yahoo.com.br

Mestranda

Universidade Federal de Minas Gerais

Rua Tamoios, 695 - Centro

30120-050 - Belo Horizonte - MG

Brasil

Palavras-chave

Biografia; História; Historiografia.

Keywords

Biography; History; Historiography. 
A biografia suscita relevantes questões teórico-metodológicas para a História desde a constituição desta como disciplina no século XIX. No entanto, os tênues e conflituosos limiares que distinguem e aproximam esse gênero narrativo da história remontam à Antiguidade. Philipe Levillain destaca que a separação entre biografia e história é herança da historiografia grega. Os gregos associavam a história a uma narrativa da coletividade, mais compromissada com a verdade, enquanto atrelavam o estilo biográfico ao panegírico, discurso elogioso e poético empregado na exaltação de grandes heróis (LEVILLAIN 2003, p. 145).

A biografia, recursivamente, provoca incômodo entre historiadores mais céticos, que a criticam apontando seus problemas para o discurso historiográfico. As críticas recorrentes à biografia histórica englobam, principalmente, três aspectos desse estilo narrativo, classificados como negativos. Um primeiro seria a proximidade da biografia com a literatura que a afastaria de um compromisso com a verdade. Em segundo lugar, a associação da biografia - em decorrência de sua aplicabilidade à exaltação de heróis - à história política tradicional, focada na figura do grande homem. O terceiro aspecto remonta à crença de que as biografias levariam à valorização de análises individuais em detrimento de análises coletivas.

Tais críticas, entretanto, não impediram que a biografia tivesse seus defensores ao longo da história e voltasse a ganhar espaço entre pesquisas historiográficas, principalmente a partir dos anos 1980. Ao longo de séculos, reflexões ora associavam ora distinguiam a biografia de outros estilos narrativos,

266 como o literário e o histórico. No seio dessas reflexões estava em voga o problema da verdade histórica para o discurso biográfico. A despeito desses "conflitos de confins", muitos estudiosos, como Beda (no século VIII) e Thomas Stanley (no século XVII), vieram em defesa da legitimidade da biografia como texto histórico (LORIGA 2011, p. 35).

Desde o século XVIII a reflexão de biógrafos já apontava para a viabilidade de uma narrativa biográfica desprovida da noção de grandeza. Loriga esclarece que ainda no século XVIII biógrafos como Samuel Johnson e James Boswell, respectivamente, já reconheciam o valor das experiências comuns e se preocupavam "em mergulhar na intimidade doméstica a fim de captar o indivíduo privado de sua máscara social" (LORIGA 2011, p. 20). A nova história cultural veio provar a possibilidade e relevância de se retratar trajetórias de indivíduos que não estão ligados à vida pública. Estudos da microhistória italiana destacaram-se nesse sentido na década de 1980, pois davam espaço a personagens anônimos. Mostravam a plausibilidade de se apreciar a trajetória de vida de pessoas que não estavam ligadas à vida pública e, tampouco, à política. As biografias, que outrora serviam para enaltecer a figura de homens públicos, exaltando-os como heróis, agora retratam, cada vez mais, as pessoas comuns.

Além disso, muitos historiadores têm provado que o fato de se privilegiar a análise de uma trajetória de vida não implica a impossibilidade de retratar o contexto social geral no qual o indivíduo está inserido. Essa perspectiva enfatiza que a oposição entre singular e coletivo é inexistente. Segundo Giovanni Levi, a biografia demanda, sim, uma redução na escala de análise, mas isso não 
significa que haverá com esse método incompatibilidade entre a história do indivíduo e a história da sociedade (LEVI 2006).

O pequeno X: da biografia à história, de Sabina Loriga, proporciona ao leitor o entendimento de como a valorização do caráter particular e único da história (conferido pela vivência pessoal de cada ser humano) - típica da biografia foi sendo apropriada pelo discurso historiográfico. De forma clara e concisa, a autora conduz o leitor a conhecer os limiares da biografia, que a aproximam e separam de disciplinas como a literatura e a história. Para tanto, Loriga enfatiza discursos de estudiosos do século XIX - dentre eles, historiadores, um filósofo e um romancista - que defenderam a dimensão individual da história proposta pela biografia. Diretora de estudos na École des Hautes Études en Sciences Sociales e responsável pelo Atelier internacional de recherches sur les usages publics du passé, Loriga possui vasta experiência em pesquisas sobre o método biográfico. Entre suas relevantes contribuições para a historiografia atual, encontram-se trabalhos sobre história e memória, a construção do tempo histórico, o uso público do passado e a relação entre a história e a biografia.

O livro aqui resenhado foi publicado em primeira edição na França em 2010, com o título Le petit x: de la biographie à I'histoire. No Brasil, O pequeno $X$, traduzido por Fernando Scheibe, integra a coleção História \& Historiografia da editora Autêntica. Concebida por Johann Gustav Droysen (1808-1884), importante historiador alemão do século XIX, a expressão do "pequeno $x^{\text {", que }}$ deu título ao livro, designa todas as idiossincrasias pertencentes ao indivíduo. Como explica Loriga

$[\ldots]$ se chamamos de $A$ o gênio individual, a saber, tudo o que um homem é, possui e faz, então esse $A$ é formado por $a+x$, em que $a$ contém tudo o que lhe vem das circunstâncias externas, de seu país, de seu povo, de sua época, etc., e em que $x$ representa sua contribuição pessoal, a obra de sua livre vontade (LORIGA 2011, p. 14).

Loriga inicia seu texto analisando os encontros e desencontros da biografia com a literatura. Segundo ela, ao longo do século XIX e no início do XX, a biografia era hostilizada no meio literário. Nesse contexto, a biografia literária era acusada de proferir um discurso falso, ser portadora de coerência excessiva e superficialidade (LORIGA 2011, p. 26). Para literatos e romancistas, a biografia era um gênero pouco estruturado e incapaz de fornecer compreensão da vida de um indivíduo.

A relação da biografia com a história também mostrou-se conflituosa por séculos. Um dos principais motivos para esses conflitos se refere à veracidade dos fatos, como já foi mencionado anteriormente. Além disso, a historiografia encarou com desconfiança a dimensão individual proposta pela biografia. Loriga salienta que o século XIX marcou a passagem de uma história plural (die Geschicten) para uma história única (die Geschicte). A história plural seria marcada pelas contribuições particulares, retrataria a vivência dos seres humanos, ressaltando sempre a importância dos mesmos enquanto sujeitos no processo histórico. Já a die Geschicte deixaria de lado as motivações pessoais para a constituição da 
História. Motivada pela consolidação de bases científicas para a disciplina, a concepção de uma história única foi marcada pela uniformização dos eventos e eliminação das idiossincrasias. Consequentemente, verificou-se o ocultamento do indivíduo nas narrativas, enquanto surgiam inúmeros relatos sem sujeitos em livros de história (LORIGA 2011, p. 12). Não obstante, a análise do singular angariou a simpatia de alguns pensadores do século XIX.

Um desses foi o inglês Thomas Carlyle (1785-1881). Formado na Universidade de Edimburgo, se dedicou inicialmente à literatura e à filosofia. Carlyle viveu em um período no qual a Inglaterra se encontrava convulsionada por movimentos populares, o que, segundo Loriga, contribuiu para que o mesmo valorizasse a dimensão histórica da sociedade e abandonasse a ficção. O pensador inglês dedicou-se a partir de então às obras historiográficas, responsáveis por todo prestígio que ele angariou entre seus contemporâneos. Nesse contexto, produziu sua célebre História da Revolução Francesa, em 1837.

A autora analisa essa obra e constata que, para esse historiador, a sociedade agrega todas as contribuições individuais, como pensamentos, ações e emoções. Portanto, todas as particularidades de cada indivíduo são vistas como integrantes do processo histórico. Carlyle defendia o protagonismo dos grandes heróis da história, deixando transparecer em sua obra as inquietações epistemológicas que envolvem a figura do herói. Portanto, Carlyle integra a lista de pensadores estudados por Loriga a buscar o "pequeno x" na história.

Além de Carlyle, alguns historiadores alemães, que lutaram para o resgate 268 da valorização do individuo e da história plural, foram considerados por Loriga. Tais historiadores fundaram uma tradição historiográfica que se opunha à tendência da filosofia da história em propor generalizações e leis gerais para história. Dentre esses pensadores, podemos citar Johann Gottfried Herder (1744-1803), que ressaltava a força das individualidades coletivas e Wilhelm Von Humboldt (1767-1835), que valorizava o conhecimento do indivíduo no mundo do saber. Loriga aponta que o indivíduo, para Humboldt, aparece como independente, insondável e portador de papel preponderante na História. Todavia, ela adverte que esse autor reconhece também a importância do contexto social para o estudo histórico. A importância da superfície social (contexto) para o entendimento da história também é valorizada por Johann Droysen. Para ele, o elemento singular (totalidades marginais) só pode ser entendido a partir da compreensão do centro determinante da totalidade (LORIGA 2011, p. 102).

Ao longo do século XIX, a historiografia alemã garantiu grandes contribuições para o método histórico (o Methodenstreit), problematizando a condição do indivíduo e a relação dele com o mundo. De acordo com Julio Bentivoglio, nesse momento, historiadores germânicos buscavam elevar o caráter científico da História, filiando-se a academias de ciências. Envolveram-se ainda em vários projetos para valorizar a história germânica, como o Monumenta Germaniae Historica e a criação do periódico Historische Zeitschrift, uma das primeiras revistas científicas de história, criada em 1859 (BENTIVOGLIO 2011, p. 84).

Nesse contexto, enquanto Humboldt apontava o ser humano como possuidor de um papel preponderante para história, Droysen defendia que a 
história demanda, necessariamente, um sujeito, um eu, portador de memória. Tal visão contestava a existência de uma história natural, uma vez que só o ser humano teria história. $O$ pequeno $x$ de Droysen garantia assim o movimento da história e fazia com que o entendimento dessa disciplina se distanciasse de critérios aplicados às ciências objetivas. Para esse autor, tudo que incluiria o pensamento não poderia ser objetivo. Portanto, de acordo com esse historiador, a história recobre a superfície terrestre (natural) "com um estrato espiritual e ético, grava nela a marca do ser humano consciente" (apud LORIGA 2011, p. 99).

Guiados pelo debate proposto por Droysen e Humboldt, historiadores como Eduard Meyer (1855-1930), Otto Hintze (1861-1940) e Friedrich Meinecke (1862-1954), resgataram, na virada do século XX, a dimensão individual no Methodenstreit. Portanto, o pensamento desses estudiosos também foi contemplado no livro $O$ pequeno $x$. Segundo a autora, o devir histórico de Meyer é marcado pelo acaso e pela livre vontade dos indivíduos que fazem a história, reforçando a ideia de inexistência de regras gerais para a história. A vontade e a conduta individual ganhavam relevância na perspectiva de Meyer, o que aproximava seu pensamento à ideia do pequeno $x$ de Droysen. Para Meyer, o fazer historiográfico demandaria escolha de fatores determinantes de uma época. Portanto, a biografia exigiria também a escolha de personagens historicamente determinantes.

Na contracorrente da oposição entre o método histórico (individualizante) e a filosofia da história (globalizante), Wilhelm Dilthey (1833-1911) buscava "dar uma envergadura filosófica à reflexão da historiografia alemã do século XIX" (LORIGA 2011, p. 123). Para esse filósofo, existiria uma distinção transcendental entre história natural e história social. Segundo Loriga, "Dilthey emprega o termo "espírito" (Geist) para exaltar a capacidade criadora do ser humano" (LORIGA 2011, p. 125). Portanto, a história espiritual seria marcada por uma conexão dinâmica (Wirkungszusammenhang) ligada à vida psíquica e valorativa dos indivíduos. A vida psíquica, por sua vez, apareceria como uma unidade composta de lembranças e vivências acumuladas, gerando memória e esquecimento.

Dilthey concebia o indivíduo como um ser social e sociável, dependente de outros para existir e se realizar. A sociedade, por outro lado, seria composta de uma diversidade de individualidades, na qual a dimensão psíquica dos sujeitos apareceria com destaque. Esse autor negava a noção do pequeno $\mathrm{x}$ ao propor que as qualidades individuais da pessoa só se constituem em sua interação com a sociedade. As relações entre indivíduo e sociedade englobariam considerações tão amplas que escapavam ao entendimento biográfico, não sendo possível explicar o grupo a partir do indivíduo ou vice-versa. Ao se descrever uma vida, um autor não deveria fragmentá-la, e sim buscar entendê-la em sua totalidade a partir da conexão psíquica dominante no indivíduo.

De acordo com a autora, para Dilthey, qualquer indivíduo poderia ser biografado, mas a forma biográfica privilegiaria o grande homem, que teria experiências duráveis. Por muito tempo, esse filósofo acreditou que a compreensão da vida do indivíduo só seria possível ao se entender o horizonte 
do outro, através da psicologia. Todavia, ao longo de sua vida foi rompendo com essa intuição psicológica, apontando que, para se compreender o outro, era preciso partir de sua interioridade, revelada pelos seus feitos e ações.

Loriga retrata ainda o pensamento do historiador da arte, Jacob Burckhardt (1818-1897). Esse também sobrepunha as particularidades individuais aos acontecimentos gerais, por acreditar que, se tratando de história, a verdadeira atividade se encontraria na intuição e no pensamento. Burckhardt não acreditava na existência de um método universal válido para o conhecimento histórico. Para ele, a narrativa historiográfica não deveria ser constituída a partir de fórmulas prontas, mas partiria da experiência pessoal de cada pesquisador. A perspectiva de Burckhardt valorizava a importância da imaginação para a história. Ele defendia que a imaginação poética da história não a relevaria a ficção, pelo contrário, viabilizaria a reflexão e a contemplação histórica.

Segundo Loriga, a obra de Burckhardt possui uma narrativa individualizante, que enfoca a contribuição das particularidades individuais no processo histórico. Com a defesa de uma perspectiva singular para a história, Burckhardt concebeu o conceito de homem patológico, que foge às regras dos personagens heroicos da história tradicional e do homem providencial da filosofia. Longe das características do grande homem, o principal personagem da história seria o homem comum, mortal, que partilha dos sofrimentos e ambições terrestres e, dentro de sua autonomia, se vê interligado aos demais indivíduos da sociedade. O homem patológico possuiria valor estético e moral, conferindo "vivacidade e movimento 270 à cena histórica" (LORIGA 2011, p. 178). O método patológico de Burckhardt, segundo Loriga, teve sua origem na aceitação do sofrimento do homem comum e surgiu como oposição à teoria da perfectibilidade propagada por parte da filosofia. Burckhardt criticava a crença na plenitude humana e rompia com a ideia de progresso intelectual defendido por seus contemporâneos, que, para ele, não estava relacionado a qualquer tipo de progresso técnico adquirido pelas sociedades modernas (LORIGA 1998, p. 238).

Assim como o historiador da arte Burckhardt, também Léon Tolstoi (18281910) critica a figura do herói tradicional. De acordo com Loriga, a principal obra do romancista, Guerra e Paz, condena a imoralidade do grande homem, que justifica os meios pelos fins. Os heróis do romancista são, antes de tudo, sujeitos morais, que reconhecem sua dependência coletiva e renunciam à glória por se verem como simples receptáculos dos anseios de uma nação. Para a autora, Tolstoi analisava o passado esmiuçadamente e ressaltava que uma vida só tem sentido por ser uma partícula do todo (LORIGA 2011, p. 190).

Ao contrário do herói de Carlyle, o herói de Tolstoi não cristaliza os anseios e características de toda uma época. A multiplicidade de memórias relativas à vida do herói impossibilita a compreensão de todos os fatos, restando apenas fragmentos dos acontecimentos. Desse modo, ninguém pode representar sozinho toda uma época, assim como não é possível para alguém compreender a complexidade que envolve um período histórico. Contudo, como aponta Loriga, Tolstoi empreendeu a tentativa de acessar o passado ao retratar seus heróis, marcados pelas experiências sociais. A autora ressalta que o romancista 
conseguiu certo sucesso com o dilema biográfico devido a três características de sua narrativa. Para ela, esse êxito foi possível "personalizando a ação, multiplicando os pontos de vista, e dando livre curso ao movimento contínuo dos indivíduos e das situações" (LORIGA 2011, p. 207).

A autora encerra o livro $O$ pequeno $X$ com reflexões acerca das contribuições historiográficas em defesa da dimensão individual da história. Para tanto, ela situa brevemente o leitor no debate contemporâneo sobre o assunto que, desde a década de 1980, vem angariando mais adeptos no meio acadêmico. O debate contemporâneo sobre o singular e sobre a biografia, segundo a autora, democratiza a história, trazendo novas possibilidades de heróis, que são agora personagens anônimos. Desse modo, a análise de Loriga estimula estudiosos das humanidades a valorizarem as singularidades do indivíduo no devir histórico e, sobretudo, auxiliam o homem comum a pensar o seu papel na história.

O livro de Sabina Loriga é um convite a pensar a condição do indivíduo, enquanto ser sociável e social, que contribui proficuamente na construção do processo histórico. Entretanto, as reflexões que $O$ pequeno $x$ possibilita vão além da dimensão individual do devir histórico. Proporcionando uma verdadeira viagem às perspectivas historiográficas do século XIX, o livro retrata considerações de importantes pensadores que nos permitem entrever as contribuições de outras áreas do conhecimento para se pensar a história e para se fazer a história.

\section{Referências bibliográficas}

BENTIVOGLIO, Julio. A Historische Zeitschrift e a historiografia alemã do século XIX. História da Historiografia, n. 6, 2011, p. 81-101.

LEVI, Giovanni. Usos da biografia. In: FERREIRA, Marieta M.; AMADO, Janaina (org.). Usos e abusos da história oral. Rio de Janeiro: Ed. FGV, 2006, p. 167-182.

. Sobre a micro-história. In: BURCKE, Peter (org.). A escrita da história: novas perspectivas. São Paulo: UNESP, 1992, p. 135-163.

LEVILLAIN, Philipe. Os protagonistas: da biografia. In: RÉMOND, René (org.). Por uma História Política. Rio de Janeiro: Ed. UFRJ, 1996, p. 148-149.

LORIGA, Sabina. O pequeno x: da biografia à história. Belo Horizonte: Autêntica, 2011.

. A biografia como problema. In: REVEL, Jacques. Jogos de escala: a experiência da microanálise. Rio de Janeiro: Ed. FGV, 1998, p. 225-247. 